DOI: $10.17516 / 1997-1370-0768$

УДК 316.353-056.317

\title{
A New Dimension of the Social Structure of the Cognitive Society "Knowledge-class» and its Class Definiteness
}

\author{
Olga M. Khomushkua, Natalia V. Krivoviaz ${ }^{a}$ \\ and Maria S. Kukhtab* \\ ${ }^{a}$ Tuvan State University \\ Kyzyl, Republic Tuva, Russian Federation \\ ${ }^{b}$ Tomsk Polytechnic University \\ Tomsk, Russian Federation
}

Received 22.03.2021, received in revised form 12.04.2021, accepted 24.05.2021

\begin{abstract}
The article outlines the principles of class definition of the cognitive society's social structure element called «Knowledge-class» and reveals the features of the indicated phenomenon. Showing the specificity of the new dimension of the cognitive society's social structure, the author proceeds from the fact that this specificity is organically linked to the formation of new social resources, such as knowledge and information, the ability to manage knowledge and information, and the ability to control. The logic of the «Knowledge-class» concept formation (R. Dahrendorf, R. Florida, P. Drucker, F. Machlup) is revealed and the properties and characteristics of a new element of the cognitive society's social structure are indicated.
\end{abstract}

Keywords: knowledge, information, bureaucratic hierarchy, technotronic society, cognitive society, technostructure, decision making, intellectual class theory, management, intellectual worker, mobility, independence from property, educational standards, types of capital (human, intellectual, structural); «internal property», post-materialistic values, inalienable property, class self-replication, creativity, creative economy.

Research area: culturology.

Citation: Khomushku, O.M., Krivoviaz, N.V., Kukhta, M.S. (2021). A new dimension of the social structure of the cognitive society «Knowledge-class» and its class definiteness. J. Sib. Fed. Univ. Humanit. Soc. Sci., 14(6), 890-896. DOI: 10.17516/1997-1370-0768.

(C) Siberian Federal University. All rights reserved

* Corresponding author E-mail address: awatanchik@yandex.ru, eukuh@mail.tomsknet.ru,hom17@mail.ru ORCID: 0000-0002-5280-4911 (Khomushku); 0000-0001-6987-7204 (Krivovyaz); 0000-0001-8643-785X (Kukhta)

$$
-890-
$$




\title{
Новое измерение социальной структуры когнитивного общества «knowledge-class» и его классовая определенность
}

\author{
О.М. Хомушку ${ }^{a}$, Н.В. Кривовяза ${ }^{a}$ М.С. Кухтаб \\ атувинский государственный университет \\ Российская Федерация, Республика Тывва, Кьзыл \\ ${ }^{\sigma}$ Национальный исследовательский \\ Томский политехнический университет \\ Российская Федераичия, Томск
}

\begin{abstract}
Аннотация. В статье обозначены принципы классовой определенности элемента социальной структуры когнитивного общества, именуемого «knowledge-class», раскрыты особенности обозначенного феномена. Показывая специфику нового измерения социальной структуры когнитивного общества, авторы исходят из того, что эта специфика органично связана с формированием новых социальных ресурсов, ими выступают знания и информация, возможность управления знаниями и информацией, возможность контроля. Раскрыта логика формирования понятия «knowledge-class» (Р. Дарендорф, Р. Флорида, П. Друкер, Ф. Махлуп), обозначены свойства и характеристики нового элемента социальной структуры когнитивного общества.
\end{abstract}

Ключевые слова: знание, информация, бюрократическая иерархия, технотронное общество, когнитивное общество, техноструктура, принятие решений, теория класса интеллектуалов, управление, интеллектуальный работник, мобильность, независимость от собственности, стандарты образования, виды капитала (человеческий, интеллектуальный, структурный), «внутренняя собственность», постматериалистические ценности, неотуждаемая собственность, самовоспроизводство класса, креативность, креативная экономика.

Научная специальность: 24.00.00 - культурология.

Постиндустриальное общество формирует усложнение существующих отношений; уже имеющаяся классовая структура также приобретает иное измерение, что оказывается органично связанным с формированием новых ресурсов производства. В совокупности этих новых ресурсов - знание и информация, возможность их использования, возможность их контролирования. Для обозначения тех, кто использует и контролирует обозначенные ресурсы, западными теоретиками введен и термин «knowledgeclass»». В российском аналитическом опыте knowledge-class именуется классом интеллектуалов, - речь идет о современной социальной элите, «правящем классе посткапиталистического общества», управленцах промышленных компаний и тех, кто может быть включен в высший слой государственной бюрократии в системе бюрократической иерархии (Dahrendorf, 1959: 300-301). Такое содержательное наполнение дал Р. Дарендорф термину «knowledge-class» в работе 1959 года «Классы и классовые конфликты в индустриальном обществе». Позднее к потенциалу введенного Р. Дарендорфом понятийного конструкта обратились многие из тех, кто может быть назван сегодня в числе новаторов западной теории knowledge-class. Например, 3. Бжезинский интерпретирует knowledge-class в теории технотронного общества как важнейшую составную часть новой элиты, ориентирующей направленность тех процессов, 
которые заложены в логике эволюции технологического прогресса (Brzezinski, 1970: 8-9). Дж.К. Гэлбрейт назвал новую социальную страту техноструктурой и сделал акцент на роли этой страты в процессах групповых управленческих решений. Техноструктуре была отведена решающая роль в процессах принятия решений на таких уровнях, как национальном, отраслевом, а также на уровне нуждающейся в решении конкретной организации. Эти уровни представлены правительственной бюрократией, профессионалами и экспертами, из научного сообщества. Определяющая роль в принятии решений класса интеллектуалов позволила А. Турену в работе 1974 года «The post-industrial society. Tomorrow's social history: classes, conflicts and culture in the programmed society» отнести технократический класс к доминирующим классам и назвать его «субъектом подавления прочих классов».

Отметим, что уже в последней трети ушедшего столетия теория «класса интеллектуалов» допускала и другую интерпретацию нового класса. Ряд аналитиков отошел от акцента на статусе интеллектуалов в системе управления; акцент был смещен в сторону внутренних качеств, способностей. Так, Ф. Махлупом в работе «Производство и распространение знаний в США» используется термин «knowledgeworker», обозначающий работников интеллектуального труда как работников новой генерации, в деятельности которых с очевидностью проявила себя способность использовать знания и информацию. Статус интеллектуальных работников новой генерации в системе управления определен и рядом других свойств и характеристик класса, именуемого knowledge-class. В числе этих характеристик может быть названа значительная степень независимости от собственности на средства производства, интенсивная мобильность, ориентация на деятельность, предполагающую высокую степень самореализации, интенсивные проявления творческих начал (примечательно, что позже Р. Флорида обозначил работников подобного типа тер- мином «творческий класс» (Florida, 2007)). Ситуация была подытожена Д. Беллом, полагавшим, что в то время как в течение последнего столетия в производстве доминировали предприниматель, бизнесмен, руководитель промышленного предприятия, «новыми людьми» постиндустриальной эпохи стали люди знания - ученые, математики, экономисты и представители новых интеллектуальных технологий, те, кто способен привнести в процессы группового принятия решений специальные знания, талант, опыт, кто умело манипулирует уникальными знаниями и информацией на всех уровнях принятия решений, включая уровень отдельной организации, уровень отраслевой, наконец, уровень национальный. И хотя в концептуальном смысле процесс становления «класса интеллектуалов» далеко не завершенный процесс, основные признаки и доминирующие особенности общности, получившей название «knowledge-class», обретают форму систематизированного целого. В совокупности этих признаков аналитики выделяют высокие стандарты образования, что вызвано в том числе и ростом технологического уровня промышленного производства (в США до 60 \% валового национального продукта создают отрасли, в которых производство базируется на использовании знаний, - так называемый сегмент knowledge industries. Однако аналитиками отмечена деталь немаловажного свойства, существенная для оценки ситуации: статус и принадлежность к «классу интеллектуалов» определены не только высокими стандартами образования, допускаемыми, принимаемыми и требуемыми в среде, скажем высших менеджеров крупных компаний, но и, что особенно важно, тем, насколько эти стандарты превосходят стандарты средних работников, представляющих совокупную рабочую силу. Степень разрыва образовательных стандартов - причина наблюдаемого и отмеченного В. Л. Инозмецевым (Inozemtsev, 2000) явления: границы «класса интеллектуалов» никогда не могут расшириться до масштабов общества в целом. 
Западные авторы, обращаясь к проблеме классовой определенности класса интеллектуалов, делают акцент на независимости этого классового сегмента от класса буржуазии, считавшегося традиционным. Эта независимость во многом обусловлена ситуацией, когда представители новой социальной группы превращаются в обладателей возможности приобретения средств производства в личную собственность, - на смену тенденции отделения капитала от работника приходит тенденция, отражающая явление их слияния. В условиях проявления этой тенденции осуществляется становление класса, не нуждающегося в эксплуатации других социальных групп, чтобы обозначить свою особую роль в новой социальной структуре. Об этом явлении пишут Т. Сакайя, Р. Озаки, обращая внимание на предпосылку, что доступностью информационных технологий объяснимо то, что интеллектуальный работник имеет возможность индивидуального производства для рынка готовых информационных продуктов, что меняет структуру рынка рабочей силы. Эта ситуация порождает в проблемном горизонте науки новую совокупность проблем - о различных видах капитала (человеческом, интеллектуальном, структурном). Он не воплощен в материальных объектах, но персонифицирован в конкретных носителях. Аналитики вводят понятия «внутренняя собственность» («non-ownership», «intra-property»), «не собственность» («non-ownership»), отмечая формирование нового явления: превращение знания и информации в доминирующий ресурс, права владения которым ограничены и во многом условны, ведет к потере собственностью своего значения.

Трансформация статуса и роли форм собственности, ранее считавшихся традиционными, вызывает то, что властью и влиянием начинает обладать «класс интеллектуалов» (Drucker, 1996: 98-99). Его важнейшей особенностью и измерением является редкостная востребованность в вертикали социальной иерархии, высокая степень мобильности. М. Аль- броу и Х. Хендерсон, отмечая специфику нового измерения социальной структуры когнитивного общества и классовую определенность класса интеллектуалов, пишут о ситуации, в которой социальные отношения превращены скорее в сферу личных устремлений, нежели в сферу бюрократического регулирования. В этом случае, полагают авторы, оказывается возможной реализация в известной степени утопической идеи: знания, опыт, творческий потенциал сотрудника становятся безграничным ресурсом процедур решения задач и принятия решений; для этой ситуации «совместимость ценностей, мировоззрений и целей более важна, чем детали конкретной коммерческой сделки», отсюда взаимозависимость субъектов иерархии. Работники - собственники знаний, отсюда и специфика управления: управлять так, словно сотрудник является членом добровольной организации и его уход из компании - естественное проявление роста личностного потенциала сотрудника (П. Друкер, И. Накаучи). В работе «Новая реальность» П. Друкер развивает этот тезис в следующем направлении. Автор пишет о статусе владеющих знанием и информацией и имеющих высокий уровень квалификации. Этот статус, полагает автор, дает возможность обладающему им выйти за пределы эксплуатации, понимаемой традиционно, превращает «класс интеллектуалов» в самовоспроизводящуюся замкнутую общность, члены которой, будучи работниками интеллектуального труда, «... не ощущают, что их эксплуатируют как класс ... и, даже меняя свою работу ... не меняют своих экономических и социальных позиций» (Drucker, 1996: 23). Последние заключены в следовании идее приверженности целям самосовершенствования, превалирующим над целями сугубо материального свойства.

Обратимся к интересной детали, значимой в понимании природы и классовой определенности тех, кто именуется knowledge-class. Эта деталь отмечена многими из тех, кто исследует специфику класса интеллектуалов (В.Л. Иноземцев, Ф. 
Инглегарт, П. Друкер, Р. Озаки, В. Рес-Могг) Авторы относят knowledge-class к группе наиболее обеспеченных, отождествляя этот класс с верхушкой социальной пирамиды (статистические данные говорят о том, что миллион состоятельных американцев (данные представлены исследованиями В.Л. Иноземцева) включает в себя 40 \% тех, кто представляет творческие профессии, и $60 \%$ тех, кто является наемными менеджерами крупных компаний. Выходцы из семей этого социального слоя - носители и приверженцы постматериалистических ценностей, формируемых миром семьи и уже достигнутым благосостоянием; и формирование нового типа работника аналитики относят к числу наследственных, интергенерационных процессов. Например, В.Л. Иноземцев и Р. Инглегарт отмечают в этой связи, что приход к постматериализму (к постматериалистической системе ценностей) - обыденность для тех, для кого пользование всеми материальными благами привычно с детства. Класс интеллектуалов устойчив, способен к самопроизводству и самоутверждению; класс интеллектуалов, владея неотчуждаемой собственностью на знания и информацию, выведен за пределы традиционно интерпретируемой эксплуатации, замкнут в своих пределах, способен к самовоспроизводству, привержен идее самосовершенствования; деятельность класса интеллектуалов мотивирована наследуемой системой постматериалистических ценностей.

На рубеже XX-XXI веков теория классов получила мощный импульс для дальнейшегоразвития:вышлавсветставшая бестселлером работа американского социолога, профессора Школы общественной политики Университета Дж. Мейсона (Вашингтон) Ричарда Флориды «Креативный класс. Люди, которые меняют будущее». Книга получила награду журнала «Washington Monthly» в номинации «Лучшая политическая книга» 2002 года, а два года спустя журнал «Har- vard Business Review» назвал ее одной из «Лучших инновационных идей».

В исследовании Р. Флориды креативность анализируется как новое измерение интеллектуального класса когнитивного общества. Исследование чрезвычайно многопроблемно. Раскрывая классовую определенность общности, именуемой креативным классом, Р. Флорида обращается к ряду проблем, решая которые автор в итоге интерпретирует креативный класс как целостность в социальной структуре когнитивного общества. Автор представляет измерения креативности, интерпретирует креативность как капитал и товар постиндустриального мира, как источник конкурентных преимуществ в условиях рынка, раскрывает феномен роста креативности и характерные ценности, сосуществующие с креативностью, место креативных специалистов в конкурентной среде. Одна из важнейших для автора проблем - проблема методов активного управления креативностью нового класса. И действительно, возможно ли управление творчеством? В своей позиции-ответе Р. Флорида радикален. Автор интерпретирует современную экономику как креативную экономику; это тип экономики, основанной на знании и управляемой знаниями. Обозначая контуры развития экономики знания, Р. Флорида отводит знанию роль основного экономического ресурса; главной же движущей силой является креативность, создание на базе знания новых форм. Знание и информация - орудие и рабочий материал креативности. Инновация, обретшая форму нового технологического изобретения, нового принципа управления, новой модели реализации принципов бизнеса, продукт креативности. Сам же креативный класс, владея достаточной властью, талантами, человеческими ресурсами, способен сыграть доминирующую роль в обновлении мира. Это, однако, потребует создания новых форм общественных связей, адекватных эпохе креативности. 


\section{Список литературы}

Агацци Э. (2012). Идея общества, основанного на знаниях // Вопросы философии, 10, 3-19.

Ашкеров, А. (2009). Экспертократия. Управление знаниями. Производство и обращение информации в эпоху ультракапитализма. М.: Изд-во «Европа», $128 \mathrm{c}$.

Баксанский, О.Е. (2007). Фундаментальные, прикладные и практические аспекты когнитивных наук // Когнитивный подход. М.: Эпистемология. Перспективы развития, 536 с.

Друкер, П. (1999). Посткапиталистическое общество // Новая индустриальная волна на Западе. Антология. М.: Академия.

Друкер, П. (1998). Следующая информационная револючия. Форбс.

Иноземцев, В.Л. (2000). Современное постиндустриальное общество: природа, противоречие, перспективы. М.: Логос, $304 \mathrm{c.}$

Корниенко, А.А. (2020). Когнитивно-инновачионные основания общества знания. Дискурс исследовательских традищий. Томск: Издательство политехнического университета, $207 \mathrm{c}$.

Махлуп, Ф. (1996). Производство и распространение знаний в США. М.: Прогресс.

Савельзон, О. (1984). Формализованные и автоматизированные модели принятия решений при формировании систем методик для аналитического контроля производств. М.: ГИРЕДМЕТ.

Степин, В.С. (2009). Конструктивные и прогностические функции философии // Вопросы философии, 1, 5-10.

Тоффлер, Э. (1997). Футурошок. СПб.

Флорида, Р. (2007). Креативный класс: люди, которые меняют будущее. М.: Издат. Дом «Классика-XXI», 421 с.

Хомушку, О.М., Кухта, М.С. (2016). Этноконфессиональный фактор в духовном возрождении Тувы: социально-философский анализ // Вестник Калмыцкого института гуманитарных исследований РАН, 5 (27), 119-126.

\section{References}

Agazzi, E. (2012). Ideja obshhestva, osnovannogo na znanijah [The idea of a knowledge-based society]. In Voprosy filosofii, 10, 3-19.

Ashkerov, A. (2009). Ekspertokratiya. Upravleniye znaniyami: proizvodstvo i obrashcheniye informatsii v epokhu ul'trakapitalizma [Expertocracy. Knowledge management: production and circulation of information in the era of ultracapitalism]. Moscow: Publishing house "Europe", $128 \mathrm{p}$.

Baksansky, O.E. (2007). Fundamental'nye, prikladnye i prakticheskie aspekty kognitivnyh nauk [Фундаментальные, прикладные и практические аспекты когнитивных наук]. In Kognitivnyj podhod [Cognitive approach]. Moscow: Jepistemologija. Perspektivy razvitija, $536 \mathrm{p}$.

Brzezinski, Zb. (1970). Between two ages. N.J., 334 p.

Dahrendorf, R. (1959). Class and class conflict in industrial society. Stanford, $336 \mathrm{p}$.

Drucker, P. (1962). The new Society. The anatomy of industrial ozoler. N.Y. 176 p.

Drucker, P. (1996). Landmarks of tomorrow. New Brunswick (US) - London.

Drucker, P. (1996). The new realities. Oxford.

Drucker, P. (1998). The Next Information Revolution. Forbes.

Drucker, P. (1999). Postkapitalisticheskoe obshhestvo [Post-Capitalist Society]. In Novaja industrial'naja volna na Zapade. Antologija [New post-industrial wave in the West. Anthology]. Moscow: Academy.

Drucker, P. (1999). Beyond the Information Revolution. In The Atlantic monthly, 284, 46-57.

Florida, R. (2007). Kreativnyj klass: ljudi, kotorye menjajut budushhee [Creative class: people who change the future]. Moscow: Publishing house "Klassika-XXI". 421 p. 
Inozemtsev, V.L. (2000). Sovremennoe postindustrial'noe obshhestvo: priroda, protivorechie, perspektivy [Modern post-industrial society: nature, contradictions, prospects]. Moscow: Logos, $304 \mathrm{p}$.

Kornienko, A.A. (2020). Kognitivno-innovacionnye osnovanija obshhestva znanija. Diskurs issledovatel'skih tradicij [Cognitive-innovative foundations of the knowledge society. Discourse of research traditions]. Tomsk: Tomsk Polytechnic University publishing house, $207 \mathrm{p}$.

Khomushku, O.M., Kukhta, M.S. (2016). Etnokonfessional'niy faktor v dukhovnom vozrozhdenii Tuvy: sotsial'no-filosofskij analiz [Ethno-confessional factor in the spiritual revival of Tuva: socio-philosophical analysis]. In Vestnik Kalmytskogo instituta gumanitarnykh issledovaniy RAN [Bulletin of Kalmyk Humanitarian Research Institute of the Russian Academy of Sciences], 5 (27), 119-126.

Khomushku, O.M., Kukhta, M.S., Raitina, M.Yu. (2020). Socio-cultural adaptation of Tuvan students in educational space of Tomsk. In J. Sib. Fed. Univ. Humanit. Soc. Sci., 13(7), 1137-1143. DOI: 10.17516/1997-1370-0631.

Machlup, F. (1996). Proizvodstvo i rasprostranenie znanij v SShA [The Production and Distribution of Knowledge in the United States]. Moscow: Progress.

Savelzon, O. (1984). Formalizovannye $i$ avtomatizirovannye modeli prinjatija reshenij pri formirovanii sistem metodik dlja analiticheskogo kontrolja proizvodstv [Formalized and automated models of decision making when forming systems of methods for analytical control of production]. Moscow: GIREDMET.

Stepin, V.S. (2009). Konstruktivnye i prognosticheskie funkcii filosofii [Constructive and prognostic function of philosophy]. In Voprosy filosofii [Problems of Philosophy], 1, 5-10.

Toffler, A. (1997). Futuroshok [Future Shock]. SPb.

Touraine, A. (1974). The post-industrial society. Tomorrow's social history: classes, conflicts and culture in the programmed society. London; Willwood House. 